\title{
Reference Correlation for the Density and Viscosity of Eutectic Liquid Alloys $\mathrm{Al}+\mathrm{Si}, \mathrm{Pb}+\mathrm{Bi}$, and $\mathrm{Pb}+\mathrm{Sn}$
}

\author{
M. J. Assael ${ }^{\text {a) }}$ and E. K. Mihailidou \\ Chemical Engineering Department, Aristotle University, 54124 Thessaloniki, Greece
}

\section{J. Brillo}

Institut für Materialphysik im Weltraum, Deutsches Zentrum für Luft- und Raumfahrt, 51170 Köln, Germany

\section{S. V. Stankus}

Kutateladze Institute of Thermophysics, Siberian Branch of the Russian Academy of Sciences, Lavrentyev ave. 1, 630090 Novosibirsk, Russia

\section{J. T. Wu}

Center of Thermal and Fluid Science, Xi'an Jiaotong University, Shaanxi 710049, People's Republic of China

\section{W. A. Wakeham}

Chemical Engineering Department, Imperial College, London SW7 2BY, United Kingdom

(Received 26 July 2012; accepted 20 August 2012; published online 18 September 2012)

In this paper, the available experimental data for the density and viscosity of eutectic liquid alloys $\mathrm{Al}+\mathrm{Si}, \mathrm{Pb}+\mathrm{Bi}$, and $\mathrm{Pb}+\mathrm{Sn}$ have been critically examined with the intention of establishing a reference standard representation of both density and viscosity. All experimental data have been categorized as primary or secondary according to the quality of measurement, the technique employed, and the presentation of the data, as specified by a series of carefully defined criteria. The proposed standard reference correlations for the density of liquid $\mathrm{Al}+\mathrm{Si}, \mathrm{Pb}+\mathrm{Bi}$, and $\mathrm{Pb}+\mathrm{Sn}$ are, respectively, characterized by deviations of $2.0 \%, 2.9 \%$, and $0.5 \%$ at the $95 \%$ confidence level. The standard reference correlations for the viscosity of liquid $\mathrm{Al}+\mathrm{Si}, \mathrm{Pb}+\mathrm{Bi}$, and $\mathrm{Pb}+\mathrm{Sn}$ are, respectively, characterized by deviations of $7.7 \%, 14.2 \%$, and $12.4 \%$ at the $95 \%$ confidence level. (c) 2012 American Institute of Physics. [http://dx.doi.org/10.1063/1.4750035]

Key words: bismuth; density; eutectic; lead; metal; reference correlations; tin; viscosity.

\section{CONTENTS}

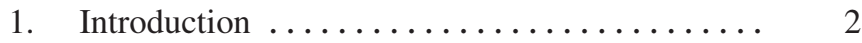

2. Primary and Secondary Data $\ldots \ldots \ldots \ldots \ldots . . \ldots . \ldots . \ldots . \ldots$

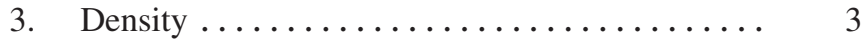

3.1. Experimental techniques............ 3

3.2. Data compilation ................ 3

3.3. Density reference correlation $\ldots \ldots \ldots \ldots \ldots$

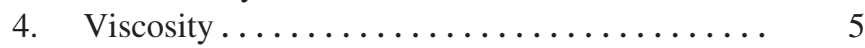

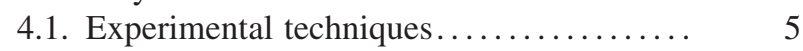

4.2. Data compilation ................. 5

4.3. Viscosity reference correlation.......... 7

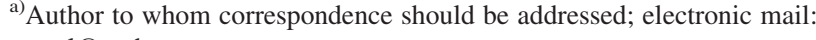
assael@auth.gr.

(c) 2012 American Institute of Physics.
}

5. Conclusions $\ldots \ldots \ldots \ldots \ldots \ldots \ldots \ldots \ldots \ldots . \ldots \ldots$

Acknowledgments ................. 9

6. References .................... 9

\section{List of Tables}

1. Data sets considered for the density of liquid eutectic $\mathrm{Al}+\mathrm{Si}, \mathrm{Pb}+\mathrm{Bi}$, and $\mathrm{Pb}+\mathrm{Sn} . . . \ldots \ldots \ldots . . . .4$

2. Temperature range, coefficients, and deviations at the $95 \%$ confidence level of Eq. (1).......... 4

3. Recommended values for the density and viscosity of liquid eutectic alloys $\mathrm{Al}+\mathrm{Si}, \mathrm{Pb}+\mathrm{Bi}, \mathrm{Pb}+\mathrm{Sn}$. .

4. Data sets considered for the viscosity of liquid eutectic $\mathrm{Al}+\mathrm{Si}, \mathrm{Pb}+\mathrm{Bi}$, and $\mathrm{Pb}+\mathrm{Sn} . \ldots \ldots \ldots \ldots$ 
5. Temperature range, coefficients, and deviations at the $95 \%$ confidence level of Eq. (2)

\section{List of Figures}

1. Primary density data and their percentage deviations from Eq. (1) for eutectic liquid alloy $\mathrm{Al}+\mathrm{Si}$ as a function of temperature. ...................

2. Primary density data and their percentage deviations from Eq. (1) for eutectic liquid alloy $\mathrm{Pb}+\mathrm{Bi}$ as a function of temperature. ...................

3. Primary density data and their percentage deviations from Eq. (1) for eutectic liquid alloy $\mathrm{Pb}+\mathrm{Sn}$ as a function of temperature. ...................

4. Primary viscosity data and their percentage deviations from Eq. (2) for eutectic liquid alloy $\mathrm{Al}+\mathrm{Si}$ as a function of temperature. ...................

5. Primary viscosity data and their percentage deviations from Eq. (2) for eutectic liquid alloy $\mathrm{Pb}+\mathrm{Bi}$ as a function of temperature. ...................

6. Primary viscosity data and their percentage deviations from Eq. (2) for eutectic liquid alloy $\mathrm{Pb}+\mathrm{Sn}$ as a function of temperature.....................

\section{Introduction}

Following the need for reference values of the density and viscosity of liquid metals identified over several years, a project was initiated by the International Association for Transport Properties, IATP (former Subcommittee on Transport Properties of the International Union of Pure and Applied Chemistry, IUPAC) in 2006 to evaluate critically the density and the viscosity of selected liquid metals. Thus,

- in 2006, reference values for the density and viscosity of liquid aluminum and iron were published, ${ }^{1}$ as a result of a project supported by IUPAC.

- Following this, in 2010, values for the density and viscosity for liquid copper and tin were proposed. ${ }^{2}$ That work had also been supported by IUPAC.

- In 2011, the work was continued and reference correlations of the density and viscosity of liquid bismuth, nickel, lead, silver and antimony were proposed, ${ }^{3}$ while in 2012 the work was concluded with liquid cadmium, cobalt, gallium, indium, mercury, silicon, thallium, and zinc. ${ }^{4}$

For the remaining liquid metals in the periodic table, very limited information is available in the literature.

The present work proposes reference correlations for the liquid eutectic alloys $\mathrm{Al}+\mathrm{Si}, \mathrm{Pb}+\mathrm{Bi}$, and $\mathrm{Pb}+\mathrm{Sn}$. These three eutectic alloys were selected because measurements for their density and viscosity are available from several sources. The following should also be noted:
- Alloy $\mathrm{Al}+\mathrm{Si}$ shows a eutectic concentration at $12.0 \%$ by mass $(11.53 \%$ by atom) of $\mathrm{Si}$, and it is employed by the metal casting industry and in functionally graded materials (FGM).

- Alloy $\mathrm{Pb}+\mathrm{Bi}$ shows a eutectic concentration at $55.5 \%$ by mass $(56.25 \%$ by atom) of $\mathrm{Bi}$, and is employed as a coolant in primary circuits in nuclear reactors.

- Alloy $\mathrm{Pb}+\mathrm{Sn}$ shows a eutectic concentration at $61.9 \%$ by mass $(73.9 \%$ by atom) of $\mathrm{Sn}$, and is employed in the 5 electronic industry.

\section{Primary and Secondary Data}

According to the recommendation adopted by the Subcom5 mittee of Transport Properties (now known as The International Association for Transport Properties) of the International Union of Pure and Applied Chemistry, experimental data can be placed into two categories according to the quality of the data: primary and secondary data. As already discussed, ${ }^{1-4}$ the primary data are identified by the following criteria: ${ }^{5}$

(i) Measurements must have been made with a primary experimental apparatus, i.e., one for which a complete working equation is available.

(ii) The form of the working equation should be such that sensitivity of the property measured to the principal variables does not magnify the random errors of measurement.

(iii) All principal variables should be measurable to a high degree of precision.

(iv) The published work should include some description of purification methods and a guarantee of the purity of the sample.

(v) The data reported must be unsmoothed data. While graphs and fitted equations are useful summaries for the reader, they are not sufficient for standardization purposes.

(vi) The lack of accepted values of the density and viscosity of standard reference materials implies that only absolute, and not relative, measurement results can be considered.

(vii) Explicit quantitative estimates of the uncertainty of reported values should be given, taking into account the precision of experimental measurements and possible systematic errors.

(viii) Owing to the desire to produce reference values of low uncertainty, limits must be imposed on the uncertainty of the primary data sets. These limits are determined after critical evaluation of the existing data sets.

These criteria have been successfully employed to propose standard reference values for the viscosity and thermal conductivity of fluids over a wide range of conditions, with uncertainties in the region of $1 \%$.

However, in the case of the liquid metals and their alloys, it was argued that these criteria needed to be relaxed slightly, 
since the uncertainty of the measurements is generally much higher, primarily owing to (i) the difficulties associated with the techniques employed at such high temperatures and (ii) the purity of the liquid metal sample which can be strongly affected by the surrounding atmosphere and the container used for the melt.

\section{Density}

\subsection{Experimental techniques}

Among the experimental work identified for the density of molten materials, a large number of techniques have been employed to measure the density of eutectic liquid alloys $\mathrm{Al}+\mathrm{Si}, \mathrm{Pb}+\mathrm{Bi}$, and $\mathrm{Pb}+\mathrm{Sn}$. Methods employed include: Archimedean; pycnometric; bubble-pressure; sessile-drop; large-drop; levitation; and gamma radiation attenuation. These methods have been presented in our previous compilations ${ }^{1-4}$ and will not be further discussed here; nothing significantly different has been applied in the work reviewed here.

It should also be noted that, although some investigators have noticed a hysteresis in the density values between heating and cooling, recent work ${ }^{6}$ has shown that this effect disappears upon proper mixing.

\subsection{Data compilation}

Table 1 presents the data sets found for the measurement of the density of eutectic liquid alloys $\mathrm{Al}+\mathrm{Si}, \mathrm{Pb}+\mathrm{Bi}$, and $\mathrm{Pb}+\mathrm{Sn}$. In this table, the purity of the components, the composition of the alloy, the technique employed and the uncertainty quoted are also presented. Furthermore, the form in which the data are presented and the temperature range covered are also noted. The data sets have been classified into primary and secondary sets according to the criteria presented in Sec. 2 and in conjunction with a review of the techniques described in our previous work. ${ }^{1-4}$ More specifically, the following can be noted.

- $\mathrm{Al} \pm \mathrm{Si}:$ Six investigators reported density measurements for this eutectic liquid alloy. The measurements of Magnusson and Arnberg ${ }^{7}$ and Siddiqui et al. ${ }^{8}$ were performed by the Archimedean technique with low uncertainty and were considered as primary data. The measurements of Wang et al. ${ }^{9}$ obtained in a sessile-drop instrument with low uncertainty were also considered as primary data together with the electromagnetic levitation measurements of Schmitz et al. ${ }^{10}$ and the $\gamma$-ray measurements of Popel et al. ${ }^{11}$ Finally, the measurements of Peijie et al. ${ }^{12}$ performed in a $\gamma$-ray instrument were considered as secondary data, because they were shown in a very small graph, as the authors were only interested in the investigation of the effect on the density of adding $\mathrm{Ce}$ in this alloy.

- $\mathrm{Pb} \pm \mathrm{Bi}$ : Density measurements have been reported by five investigators. The measurements of Stankus et al. ${ }^{13}$ and Yagodin et al. ${ }^{14}$ were performed in an absolute way, in $\gamma$-ray instruments, with low uncertainty and were thus considered as primary data. The measurements of Alchagirov et al. ${ }^{15}$ were obtained in an absolute pycnometer with very low uncertainty and were also part of the primary data. As primary data, the sessile-drop measurements of Kazakova et al. ${ }^{16}$ were also included as they covered a wide range, even if their uncertainty was worse. Finally, the measurements of Plevachuk et al. ${ }^{17}$ performed in a large-drop instrument, were considered as secondary data, as the authors themselves recognize that their data are lower than all other data.

- $\mathrm{Pb} \pm \mathrm{Sn}$ : The low-uncertainty measurements of Khairulin and Stankus, ${ }^{6}$ performed in a $\gamma$-ray instrument, of Wang and Xian, ${ }^{18}$ performed in an Archimedean apparatus, and of Thresh and Crawley, ${ }^{19}$ performed in a pycnometer, were all considered as primary data. The measurements of Gebhardt and Kostlin, ${ }^{20}$ obtained in an Archimedean apparatus, and of Fischer and Phillips, ${ }^{21}$ obtained in a maximum bubblepressure instrument, were also part of the primary data set. The measurements of Gasior et al. ${ }^{22}$ obtained in a dilatometer were considered as secondary data, as they show a distinctively different slope than the all other measurements. The $\gamma$-ray measurements of Popel et al. ${ }^{23}$ were also considered in this case as secondary, as they deviated from all other data sets, systematically and in excess of the quoted uncertainty.

\subsection{Density reference correlation}

The primary density data for the liquid eutectic alloys, shown in Table 1, were employed in a linear regression analysis to represent the density at $0.1 \mathrm{MPa}$ as a function of the temperature. Since the quoted uncertainties of all works were of similar magnitude, the data were weighted only according to the number of points. The following equations were obtained for the density, $\rho\left(\mathrm{kg} \mathrm{m}^{-3}\right)$, as a function of the absolute temperature, $T(\mathrm{~K})$,

$$
\rho=c_{1}-c_{2} T,
$$

and the coefficients $c_{1}\left(\mathrm{~kg} \mathrm{~m}^{-3}\right)$ and $c_{2}\left(\mathrm{~kg} \mathrm{~m}^{-3} \mathrm{~K}^{-1}\right)$ are shown for each liquid eutectic alloy in Table 2. In the same table, the percentage deviation $(2 \sigma)$ of each equation at the $95 \%$ confidence level is also shown.

Figures 1-3 show the primary data and their percentage deviations from the above equation for each of the three liquid eutectic alloys. The dashed vertical line shows the melting point for each alloy. The following can be observed:

- In the case of $\mathrm{Al}+\mathrm{Si}$ (Fig. 1), although most investigators quote uncertainty below $1 \%$, their measurements differ among themselves by up to $1.5 \%$.

- In the case of $\mathrm{Pb}+\mathrm{Bi}$, the measurements of Kazakova et al. ${ }^{16}$ and Yagodin et al. ${ }^{14}$ are further apart than the other two sets. However, as already stated, there is no justification not to consider them as primary data. Therefore, the deviations are within $2.9 \%$ at the $2 \sigma$ confidence level. It should be pointed out that in the case of the $\mathrm{Pb}-\mathrm{Bi}$ eutectic, 
TABLe 1. Data sets considered for the density of liquid eutectic $\mathrm{Al}+\mathrm{Si}, \mathrm{Pb}+\mathrm{Bi}$, and $\mathrm{Pb}+\mathrm{Sn}$.

\begin{tabular}{|c|c|c|c|c|c|c|c|c|}
\hline First author & $\begin{array}{r}\text { Publ. } \\
\text { year }\end{array}$ & Technique employed ${ }^{\mathrm{a}}$ & $\begin{array}{l}\text { Purity }^{\mathrm{b}} \\
(\text { mass \%) }\end{array}$ & $\begin{array}{c}\text { Composition }^{\mathrm{c}} \\
(\text { mass } \%)\end{array}$ & $\begin{array}{l}\text { Uncertainty } \\
\text { quoted }(\%)\end{array}$ & $\begin{array}{c}\text { No. of } \\
\text { data }\end{array}$ & $\begin{array}{c}\text { Form of } \\
\text { data }^{\mathrm{d}}\end{array}$ & $\begin{array}{c}\text { Temperature } \\
\text { range }(\mathrm{K})\end{array}$ \\
\hline & & & & $\mathrm{Al}+\mathrm{Si}$ & & & & \\
\hline \multicolumn{9}{|l|}{ Primary data } \\
\hline Schmitz $^{10}$ & 2012 & EML (Abs) & $\begin{array}{l}99.999 \\
99.999\end{array}$ & 12.0 & 1.0 & 20 & $\mathrm{P}$ & $951-1601$ \\
\hline Magnusson $^{7}$ & 2001 & Archimedean (Abs) & $\begin{array}{l}99.999 \\
99.99\end{array}$ & 11.6 & 0.3 & 8 & $\mathrm{P}$ & $871-1073$ \\
\hline Wang $^{9}$ & 2001 & Sessile drop (Abs) & $\begin{array}{l}99.995 \\
99.99\end{array}$ & 12.5 & 0.5 & 17 & $\mathrm{P}$ & $928-1454$ \\
\hline Popel $^{11}$ & 1987 & $\gamma$-ray & $\begin{array}{l}99.999 \\
99.999\end{array}$ & 12.7 & 0.07 & 17 & $\mathrm{D}$ & $872-1725$ \\
\hline Siddiqui $^{8}$ & 1987 & Archimedean (Abs) & $\begin{array}{c}99.74 \\
\text { na }\end{array}$ & 11.0 & na & 5 & $\mathrm{P}$ & $858-965$ \\
\hline $\begin{array}{l}\text { Secondary data } \\
\text { Peijie }^{12}\end{array}$ & 1996 & $\gamma$-ray (Abs) & $\begin{array}{l}\text { na } \\
\text { na }\end{array}$ & 11.7 & 0.1 & 4 & $\mathrm{D}$ & $973-1273$ \\
\hline
\end{tabular}

\begin{tabular}{|c|c|c|c|c|c|c|c|c|}
\hline \multicolumn{9}{|l|}{ Primary data } \\
\hline Stankus $^{13}$ & 2006 & $\gamma$-ray (Abs) & $\begin{array}{l}99.998 \\
99.98\end{array}$ & 55.5 & $0.3-0.4$ & 115 & $\mathrm{D}$ & $404-1224$ \\
\hline Yagodin $^{14}$ & 2005 & $\gamma$-ray (Abs) & na & 55.4 & 0.5 & 12 & $\mathrm{E}$ & $400-950$ \\
\hline Alchagirov $^{15}$ & 2003 & Pycnometer (Abs) & $\begin{array}{l}\text { na } \\
\text { na }\end{array}$ & 55.5 & 0.1 & 83 & $\mathrm{P}$ & $410-726$ \\
\hline Kazakova $^{16}$ & 1984 & Sessile drop & $\begin{array}{l}99.999 \\
99.999\end{array}$ & 56.7 & 2.0 & 9 & $\mathrm{E}$ & $400-1200$ \\
\hline $\begin{array}{c}\text { Secondary data } \\
\text { Plevachuk }^{17}\end{array}$ & 2011 & Large drop & $\begin{array}{l}\text { na } \\
\text { na }\end{array}$ & 56.0 & 1.5 & 7 & $\mathrm{E}$ & $400-700$ \\
\hline \multicolumn{9}{|c|}{$\mathrm{Pb}+\mathrm{Sn}$} \\
\hline \multicolumn{9}{|l|}{ Primary data } \\
\hline Khairulin $^{6}$ & 2007 & $\gamma$-ray (Abs) & $\begin{array}{l}99.99 \\
99.99\end{array}$ & 61.9 & 0.2 & 118 & $\mathrm{D}$ & $453-1036$ \\
\hline Wang $^{18}$ & 2005 & Archimedean (Abs) & $\begin{array}{l}99.99 \\
99.99\end{array}$ & 60.0 & 0.4 & 5 & $\mathrm{P}$ & $463-570$ \\
\hline Thresh $^{19}$ & 1970 & Pycnometer (Abs) & $\begin{array}{l}99.997 \\
99.999\end{array}$ & 62.5 & 0.05 & 8 & $\mathrm{E}$ & $463-820$ \\
\hline Gebhardt $^{20}$ & 1957 & Archimedean (Abs) & $\begin{array}{l}99.99 \\
99.9\end{array}$ & 61.9 & na & 9 & $\mathrm{P}$ & $523-973$ \\
\hline Fischer $^{21}$ & 1954 & $\begin{array}{l}\text { Maximum bubble } \\
\text { pressure (Abs) }\end{array}$ & $\begin{array}{l}99.998 \\
99.98\end{array}$ & 62.05 & na & 12 & $\mathrm{D}$ & $400-950$ \\
\hline \multicolumn{9}{|l|}{ Secondary data } \\
\hline Popel $^{23}$ & 1985 & $\gamma$-ray (Abs) & $\begin{array}{l}99.9 \\
99.95\end{array}$ & 61.9 & 0.07 & 25 & $\mathrm{D}$ & $420-950$ \\
\hline Gasior $^{22}$ & 2001 & Dilatometer (Abs) & 99.995 & 61.9 & 0.5 & 15 & $\mathrm{P}$ & $564-1200$ \\
\hline
\end{tabular}

${ }^{\mathrm{a}} \mathrm{Abs}=$ absolute; EML = electromagnetic levitation; Rel $=$ relative.

${ }^{\mathrm{b}}$ Purity refers to 1 st and 2 nd component, respectively.

${ }^{\mathrm{c}}$ Composition refers to mass percentage of second component.

${ }^{\mathrm{d}} \mathrm{D}=$ diagram; $\mathrm{E}=$ equation; $\mathrm{P}=$ points.

a correlation was also proposed by Sobolev ${ }^{24}$ in 2010 . This correlation is in excellent agreement with the present one.

- In the case of $\mathrm{Pb}+\mathrm{Sn}$, the deviations were less than $0.4 \%$ at the $2 \sigma$ confidence level.

Finally, in Table 3, density values calculated with the use of Eq. (1) are shown.
TABLE 2. Temperature range, coefficients, and deviations at the $95 \%$ confidence level of Eq. (1).

\begin{tabular}{ccccc}
\hline \hline & $\begin{array}{c}T_{\text {range }} \\
(\mathrm{K})\end{array}$ & $\begin{array}{c}c_{1} \\
\left(\mathrm{~kg} \mathrm{~m}^{-3}\right)\end{array}$ & $\begin{array}{c}c_{2} \\
\left(\mathrm{~kg} \mathrm{~m}^{-3} \mathrm{~K}^{-1}\right)\end{array}$ & $\begin{array}{c}\text { Deviation } \\
(2 \sigma)(\%)\end{array}$ \\
\hline $\mathrm{Al}+\mathrm{Si}$ & $858-1700$ & 2603 & 0.241 & 2.0 \\
$\mathrm{~Pb}+\mathrm{Bi}$ & $400-1225$ & 10922 & 1.096 & 2.9 \\
$\mathrm{~Pb}+\mathrm{Sn}$ & $400-1040$ & 8472 & 0.810 & 0.4 \\
\hline
\end{tabular}

\section{J. Phys. Chem. Ref. Data, Vol. 41, No. 3, 2012}




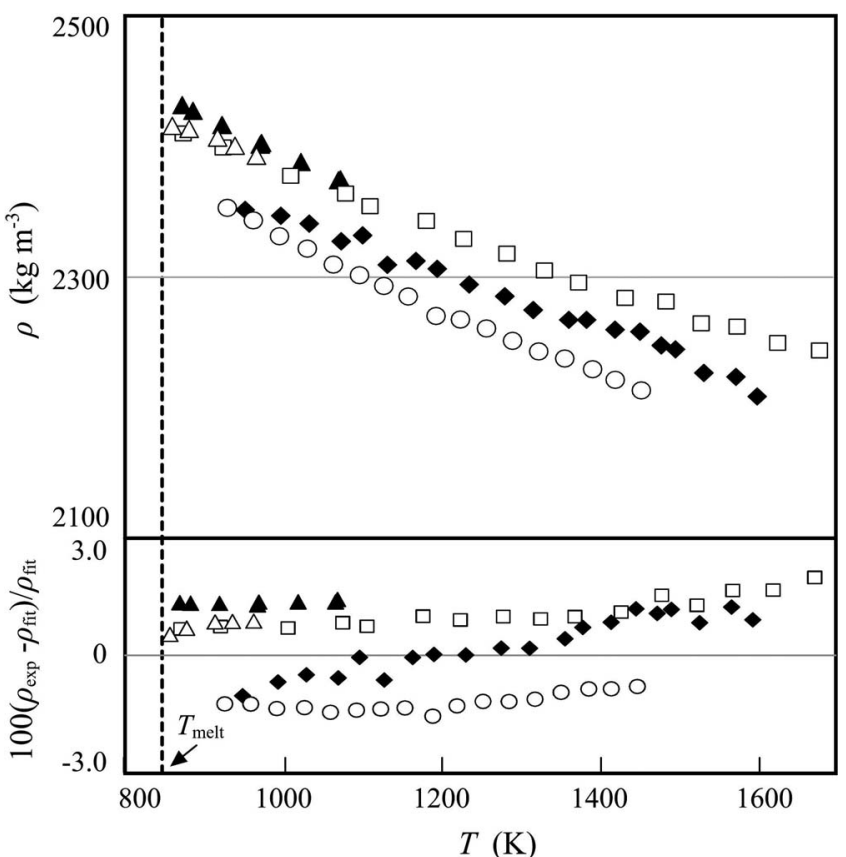

FIG. 1. Primary density data and their percentage deviations from Eq. (1) for eutectic liquid alloy $\mathrm{Al}+\mathrm{Si}$ as a function of temperature. Schmitz et al. ${ }^{10}(\diamond)$, Magnusson and Arnberg $^{7}(\boldsymbol{\Delta})$, Wang et al. ${ }^{9}(\circ)$, Popel et al. ${ }^{11}(\square)$, and Siddiqui et $a l .{ }^{8}(\Delta)$.

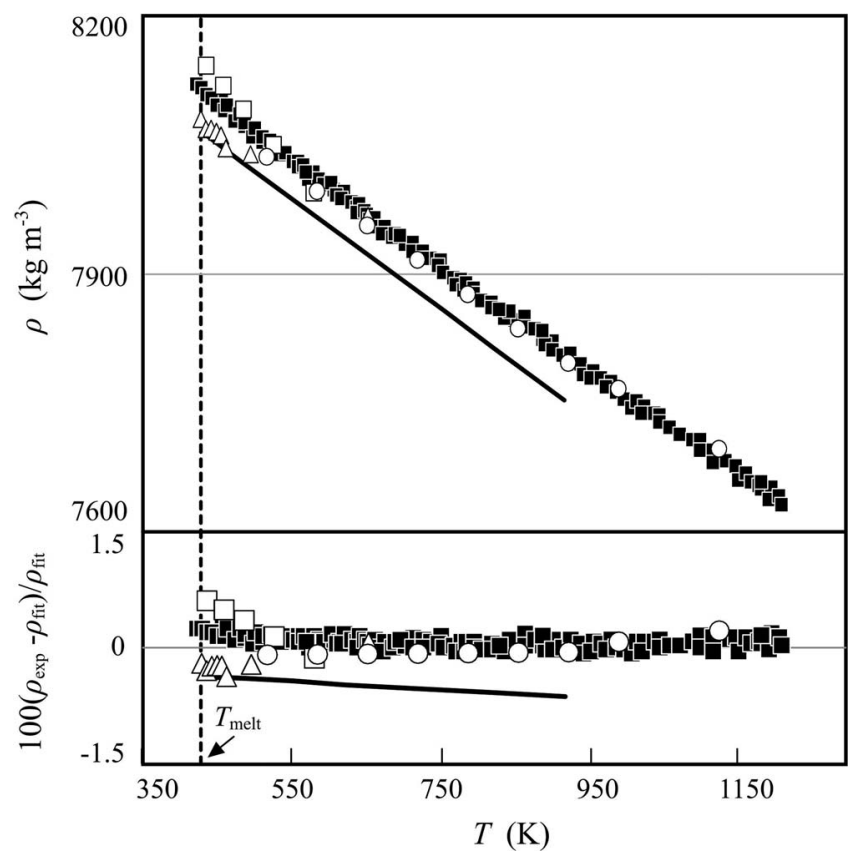

FIG. 3. Primary density data and their percentage deviations from Eq. (1) for eutectic liquid alloy $\mathrm{Pb}+\mathrm{Sn}$ as a function of temperature. Khairulin and Stankus ${ }^{6}(\square)$, Wang and Xian ${ }^{18}(\square)$, Thresh and Crawley ${ }^{19}(-)$, Fischer and Phillips $^{21}(\Delta)$, and Gebhardt and $\operatorname{Kostlin}^{20}(0)$.

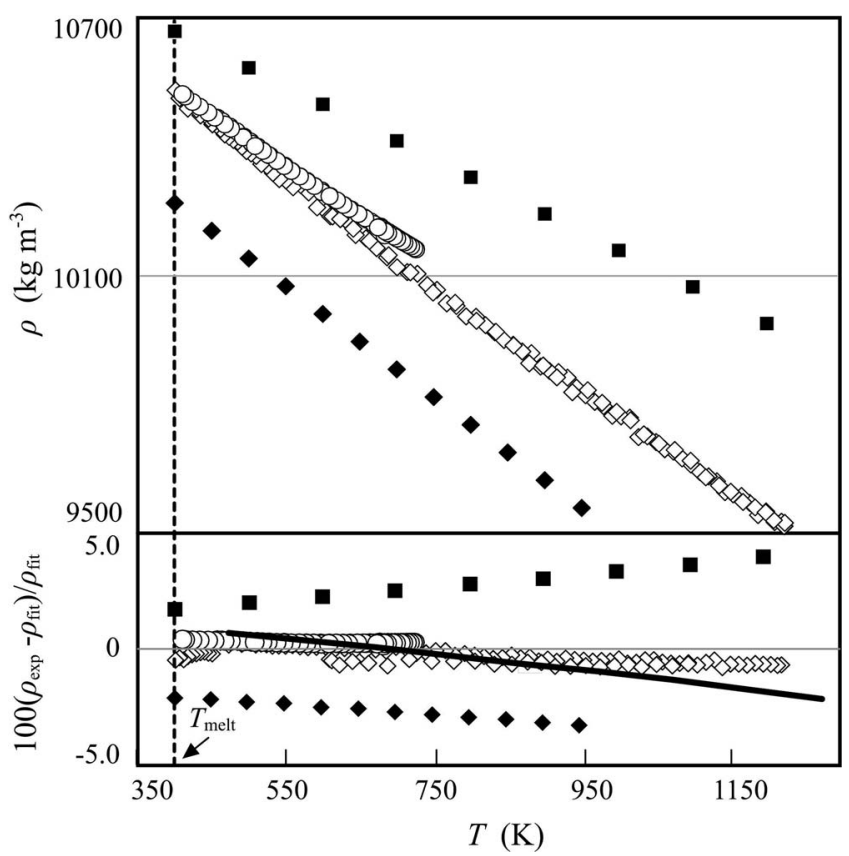

FIG. 2. Primary density data and their percentage deviations from Eq. (1) for eutectic liquid alloy $\mathrm{Pb}+\mathrm{Bi}$ as a function of temperature. Stankus et al. ${ }^{13}(\diamond)$, Yagodin et al. ${ }^{14}(\square)$, Alchagirov et al. ${ }^{15}(\circ)$, and Kazakova et al. ${ }^{16}(\diamond)$.

\section{Viscosity}

\subsection{Experimental techniques}

There exist a large number of methods to measure the viscosity of liquids, but those suitable for liquid metals are limited by the low viscosities of metals (of the order of 1-10 $\mathrm{mPa} \mathrm{s}$ ), their chemical reactivity, and generally high melting points. In the case of the three eutectic alloys examined, three techniques in total were employed: the oscillating cup, $\gamma$-rays, and the Archimedean technique. These methods have been presented in our previous compilations ${ }^{1-4}$ and will not be discussed further here.

\subsection{Data compilation}

Table 4 presents the data sets found for the measurement of the viscosity of eutectic liquid alloys $\mathrm{Al}+\mathrm{Si}, \mathrm{Pb}+\mathrm{Bi}$, and $\mathrm{Pb}+\mathrm{Sn}$. In the table, for every data set, the technique employed, the purity of the components, the composition of the alloy, the uncertainty quoted, the form of the data presented, the number of data points as well as the temperature range to which they refer, are also shown. The data sets have been classified into primary and secondary sets according to the criteria presented in Sec. 2 and in conjunction with the techniques described previously. ${ }^{1-4}$ 
TABLE 3. Recommended values for the density and viscosity of liquid eutectic alloys $\mathrm{Al}+\mathrm{Si}, \mathrm{Pb}+\mathrm{Bi}, \mathrm{Pb}+\mathrm{Sn}$.

\begin{tabular}{|c|c|c|c|c|c|c|c|c|}
\hline$T(\mathrm{~K})$ & $\begin{array}{c}\rho \\
\left(\mathrm{kg} \mathrm{m}^{-3}\right)\end{array}$ & $\begin{array}{c}\eta \\
(\mathrm{mPa} s)\end{array}$ & $T(\mathrm{~K})$ & $\begin{array}{c}\rho \\
\left(\mathrm{kg} \mathrm{m}^{-3}\right)\end{array}$ & $\begin{array}{c}\eta \\
(\mathrm{mPa} \mathrm{s})\end{array}$ & $T(\mathrm{~K})$ & $\begin{array}{c}\rho \\
\left(\mathrm{kg} \mathrm{m}^{-3}\right)\end{array}$ & $\begin{array}{c}\eta \\
(\mathrm{mPa} \mathrm{s})\end{array}$ \\
\hline \multicolumn{3}{|c|}{$\mathrm{Al}+\mathrm{Si}$} & \multicolumn{3}{|c|}{$\mathrm{Pb}+\mathrm{Bi}$} & \multicolumn{3}{|c|}{$\mathrm{Pb}+\mathrm{Sn}$} \\
\hline 850 & 2398 & 0.919 & 400 & 10484 & 3.549 & 400 & 8148 & 2.986 \\
\hline 900 & 2386 & 0.850 & 500 & 10374 & 2.380 & 500 & 8067 & 2.162 \\
\hline 1000 & 2362 & 0.718 & 600 & 10264 & 1.824 & 600 & 7986 & 1.743 \\
\hline 1100 & 2338 & 0.626 & 700 & 10155 & 1.508 & 700 & 7905 & 1.494 \\
\hline 1200 & 2314 & 0.558 & 800 & 10045 & 1.307 & 800 & 7824 & 1.331 \\
\hline 1300 & 2290 & 0.506 & 900 & 9936 & 1.170 & 900 & 7743 & 1.217 \\
\hline 1400 & 2266 & & 1000 & 9826 & 1.071 & 1000 & 7662 & 1.133 \\
\hline 1500 & 2242 & & 1100 & 9716 & 0.996 & 1100 & 7581 & \\
\hline 1600 & 2217 & & 1200 & 9607 & 0.937 & & & \\
\hline 1700 & 2193 & & 1300 & 9497 & & & & \\
\hline
\end{tabular}

TABLE 4. Data sets considered for the viscosity of liquid eutectic $\mathrm{Al}+\mathrm{Si}, \mathrm{Pb}+\mathrm{Bi}$, and $\mathrm{Pb}+\mathrm{Sn}$.

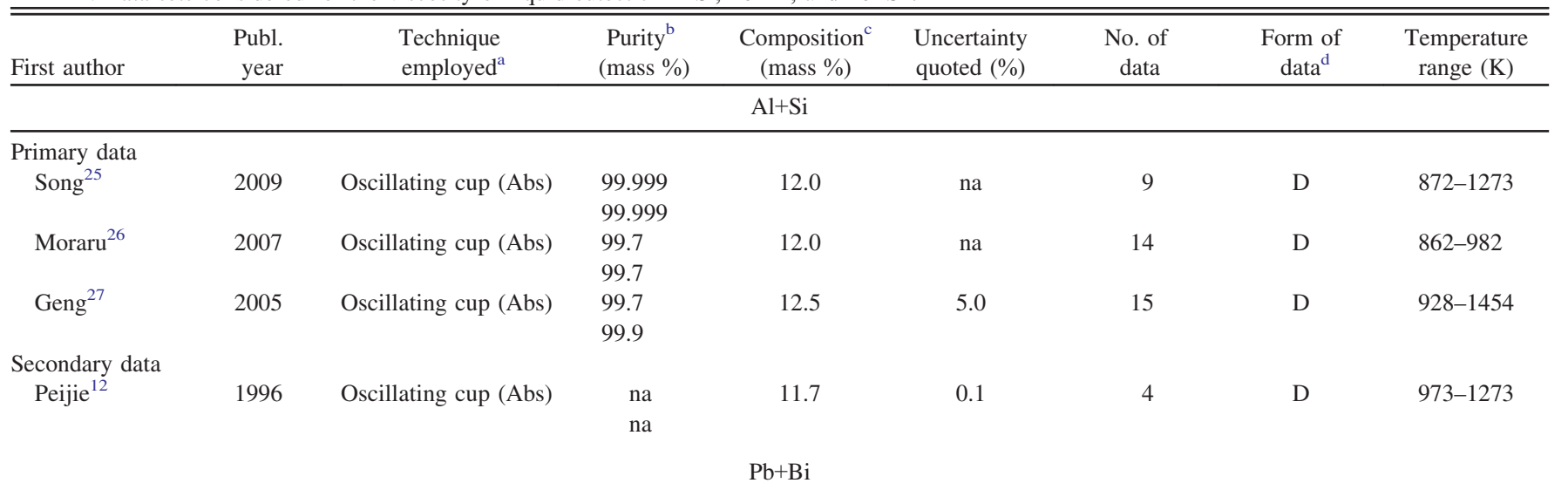

\begin{tabular}{|c|c|c|c|c|c|c|c|c|}
\hline \multicolumn{9}{|l|}{ Primary data } \\
\hline Gusachev $^{28}$ & 2011 & Oscillating cup (Abs) & na & 55.5 & 2.0 & 16 & $\mathrm{P}$ & $350-1100$ \\
\hline Plevachuk $^{29}$ & 2008 & Oscillating cup (Abs) & $\begin{array}{l}\text { na } \\
\text { na }\end{array}$ & 56.0 & 3.0 & 153 & $\mathrm{D}$ & 400-996 \\
\hline Kaban $^{30}$ & 2004 & Oscillating cup (Abs) & $\begin{array}{c}\text { na } \\
99.999 \\
99.999\end{array}$ & 55.9 & 5.0 & 136 & G & $407-1072$ \\
\hline Kaplun $^{31}$ & 1979 & Oscillating cup (Abs) & $\begin{array}{l}99.991 \\
99.992\end{array}$ & 55.5 & 5.0 & 98 & $\mathrm{P}$ & 394-1181 \\
\hline Nikol'skii ${ }^{32}$ & 1959 & Oscillating cup (Abs) & $\begin{array}{l}\text { na } \\
\text { na }\end{array}$ & 56.5 & na & 14 & $\mathrm{P}$ & $423-1073$ \\
\hline $\begin{array}{l}\text { Secondary data } \\
\mathrm{Wu}^{33}\end{array}$ & 2007 & Oscillating cup (Abs) & $\begin{array}{l}99.95 \\
99.98\end{array}$ & 55.2 & 1.0 & 14 & $\mathrm{D}$ & $398-806$ \\
\hline
\end{tabular}

\begin{tabular}{|c|c|c|c|c|c|c|c|c|}
\hline \multicolumn{9}{|l|}{ Primary data } \\
\hline Sklyarchuk $^{34}$ & 2011 & $\gamma$-ray (Abs) & $\begin{array}{l}99.99 \\
99.999\end{array}$ & 61.9 & 5.0 & 34 & $\mathrm{D}$ & $464-797$ \\
\hline Plevachuk $^{35}$ & 2005 & Oscillating cup (Abs) & $\begin{array}{l}99.999 \\
99.999\end{array}$ & 61.9 & 3.0 & 5 & $\mathrm{D}$ & $453-750$ \\
\hline Thresh $^{19}$ & 1970 & Oscillating cup (Abs) & $\begin{array}{l}\text { na } \\
\text { na }\end{array}$ & 61.9 & 0.5 & 2 & $\mathrm{D}$ & 623,823 \\
\hline $\mathrm{Kanda}^{36}$ & 1968 & Oscillating cup (Abs) & $\begin{array}{l}99.97 \\
99.999\end{array}$ & 61.9 & 1.0 & 7 & $\mathrm{D}$ & $494-770$ \\
\hline Toye $^{37}$ & 1958 & Oscillating cup (Abs) & $\begin{array}{l}99.97 \\
99.998\end{array}$ & 61.9 & 0.5 & 3 & $\mathrm{D}$ & $456-700$ \\
\hline Gebhardt $^{20}$ & 1957 & Oscillating cup (Abs) & $\begin{array}{l}99.99 \\
99.99\end{array}$ & 62.05 & 4.0 & 10 & $\mathrm{P}$ & $473-973$ \\
\hline
\end{tabular}

\section{J. Phys. Chem. Ref. Data, Vol. 41, No. 3, 2012}


TABle 4. Data sets considered for the viscosity of liquid eutectic $\mathrm{Al}+\mathrm{Si}, \mathrm{Pb}+\mathrm{Bi}$, and $\mathrm{Pb}+\mathrm{Sn}$. - Continued

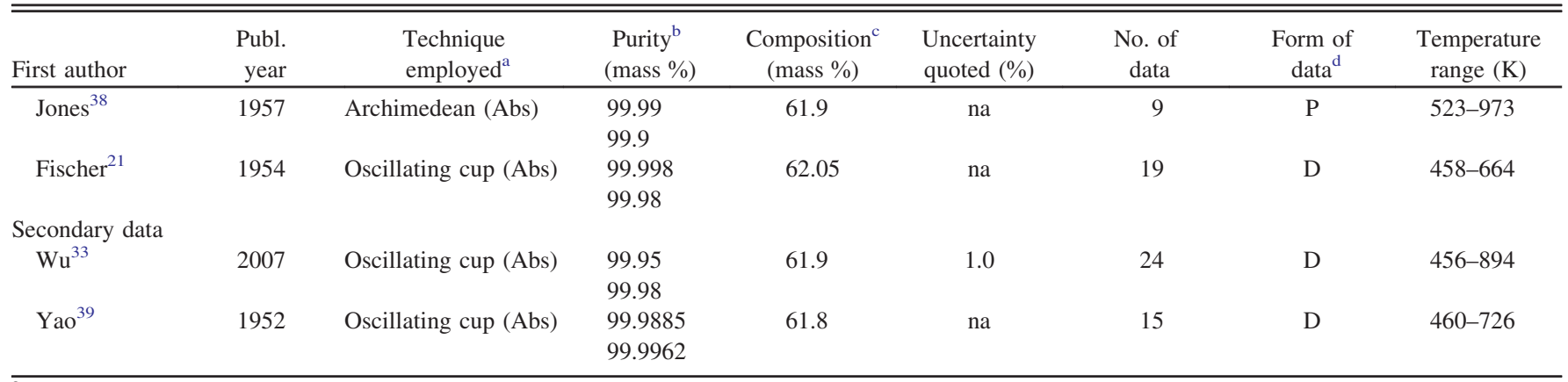

${ }^{\mathrm{a}} \mathrm{Abs}=$ absolute; Rel $=$ relative.

${ }^{\mathrm{b}}$ Purity refers to 1 st and 2 nd component, respectively.

${ }^{\mathrm{c}}$ Composition refers to mass percentage of second component.

${ }^{\mathrm{d}} \mathrm{D}=$ diagram; $\mathrm{E}=$ equation; $\mathrm{P}=$ points.

In the case of the viscosity data sets and in relation to the discussion of Sec. 4.1, the following points can be noted:

- $\mathrm{Al} \pm \mathrm{Si}:$ Four investigators reported viscosity measurements for this eutectic liquid alloy. The measurements of Song et al. ${ }^{25}$ Moraru, ${ }^{26}$ and Geng et al. ${ }^{27}$ were all performed in oscillating-cup instruments and composed the primary data set. The measurements of Peijie et al., ${ }^{12}$ performed also in an oscillating-cup instrument, were considered as secondary data, because they were shown only in a very small graph, and the authors were only interested in an investigation of the effect on viscosity when adding Ce to this alloy.

$-\mathrm{Pb}+\mathrm{Bi}$ : In the case of the measurement of the viscosity of eutectic $\mathrm{Pb}+\mathrm{Bi}$, all investigators employed the oscillatingcup technique. From the six investigators that reported viscosity measurements, Gusachev et al. ${ }^{28}$ Plevachuk et al. ${ }^{29}$ Kaban et al., ${ }^{30}$ Kaplun et al., ${ }^{31}$ and Nikol'ski et $a l^{32}$ were all considered as primary data. Gusachev et al. $^{28}$ and Nikol'ski et al. $^{32}$ reported kinematic viscosities, and thus the density equation proposed in Sec. 3 was used to convert them to dynamic viscosities. The measurements of Wu et al. ${ }^{33}$ were not included in the primary data set, as they were far higher than the measurements of all other investigators.

$-\mathrm{Pb}+\mathrm{Sn}: 10$ investigators reported measurements of the viscosity of this eutectic alloy. Eight of them were included in the primary data sets. The measurements of Plevachuk et al. ${ }^{35}$ Thresh and Crawley, ${ }^{19}$ Kanda and Colburn, ${ }^{36}$ Toye and Jones, ${ }^{37}$ Gebhardt and Kostlin, ${ }^{20}$ and Fisher and Phillips $^{21}$ were all performed in absolute oscillating-cup instruments and were part of the primary data sets. The measurements of Slyarchuk et al., ${ }^{34}$ performed in a $\gamma$-ray instrument, and the measurements of Jones and Davies, ${ }^{38}$ performed by the Archimedean technique, also formed part of the primary data sets. Among the sets of data to be considered secondary, we include the measurements of $\mathrm{Wu}$ et $a l^{33}$ and Yao and Kondic, ${ }^{39}$ whose results were much higher than all other investigators; in the case of Wu et al., ${ }^{33}$ this was also the case in $\mathrm{Pb}+\mathrm{Bi}$ measurements above, while in the case of Yao and Kondic ${ }^{39}$ the same trend was also noticed in previous evaluations. ${ }^{3,4}$

\subsection{Viscosity reference correlation}

The primary viscosity data for eutectic liquid alloys $\mathrm{Al}+\mathrm{Si}$, $\mathrm{Pb}+\mathrm{Bi}$, and $\mathrm{Pb}+\mathrm{Sn}$, shown in Table 4, were employed in a regression analysis as a function of the temperature. The data were weighted according to the number of points. The following equations were obtained for the viscosity, $\eta(\mathrm{mPa} \mathrm{s})$, as a function of the absolute temperature, $T(\mathrm{~K})$,

$$
\log _{10}\left(\eta / \eta^{\circ}\right)=-a_{1}+\frac{a_{2}}{T}
$$

where $\eta^{\circ}=1 \mathrm{mPa}$, and the coefficients $a_{1}(-)$, and $a_{2}(\mathrm{~K})$ are shown for each liquid alloy in Table 5. In the same table, the percentage deviation $(2 \sigma)$ of each equation at the $95 \%$ confidence level is also shown.

Figures 4-6 show the primary viscosity data and their percentage deviations from Eq. (2) for each liquid alloy. The dashed vertical line shows the melting point for each alloy. The following can be observed for these three figures:

- In almost all cases, the differences between authors are much larger than the claimed uncertainties, so that the overall uncertainty of the correlation is higher.

- In the case of $\mathrm{Al}+\mathrm{Si}$ eutectic alloy, more viscosity measurements are required.

TABLE 5. Temperature range, coefficients, and deviations at the $95 \%$ confidence level of Eq. (2).

\begin{tabular}{lllcc}
\hline \hline & $\begin{array}{c}T_{\text {range }} \\
(\mathrm{K})\end{array}$ & $\begin{array}{c}a_{1} \\
(-)\end{array}$ & $\begin{array}{c}a_{2} \\
(\mathrm{~K})\end{array}$ & $\begin{array}{c}\text { Deviation }(2 \sigma) \\
(\%)\end{array}$ \\
\hline $\mathrm{Al}+\mathrm{Si}$ & $860-1275$ & 0.8022 & 658.34 & 7.7 \\
$\mathrm{~Pb}+\mathrm{Bi}$ & $350-1185$ & 0.3173 & 346.95 & 14.2 \\
$\mathrm{~Pb}+\mathrm{Sn}$ & $450-975$ & 0.2266 & 280.69 & 12.4 \\
\hline
\end{tabular}




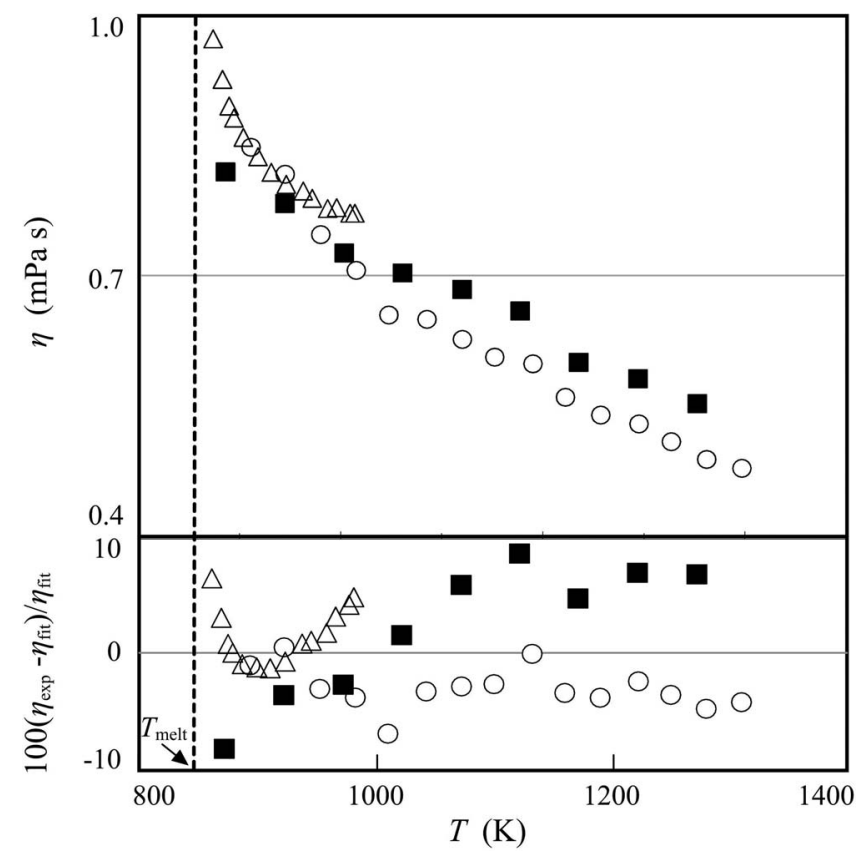

FIG. 4. Primary viscosity data and their percentage deviations from Eq. (2) for eutectic liquid alloy $\mathrm{Al}+\mathrm{Si}$ as a function of temperature. Song et $a l^{25}(\mathbf{\bullet})$, Moraru $^{26}(\Delta)$, and Geng et al. ${ }^{27}(\mathrm{O})$.

- In the case of $\mathrm{Pb}+\mathrm{Bi}$ and $\mathrm{Pb}+\mathrm{Sn}$ eutectic alloys, better measurements of lower uncertainty are required.

Viscosity values calculated from the above equation are contained in Table 3.

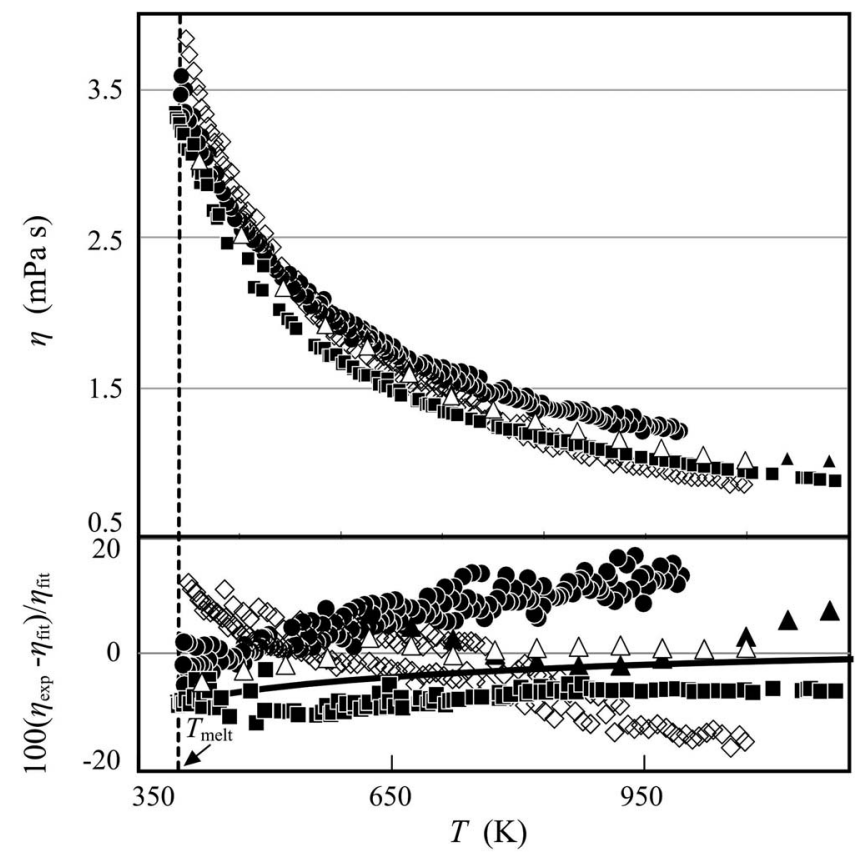

FIG. 5. Primary viscosity data and their percentage deviations from Eq. (2) for eutectic liquid alloy $\mathrm{Pb}+\mathrm{Bi}$ as a function of temperature. Gusachev et al. ${ }^{28}$ $(\boldsymbol{\Delta})$, Sobolev $^{24}(-)$, Plevachuk et al. ${ }^{29}(\bullet)$, Kaban et $a l^{30}(\diamond)$, Kaplun et al. ${ }^{31}(\mathbf{\square})$, and Nikol'ski et al. ${ }^{32}(\Delta)$.

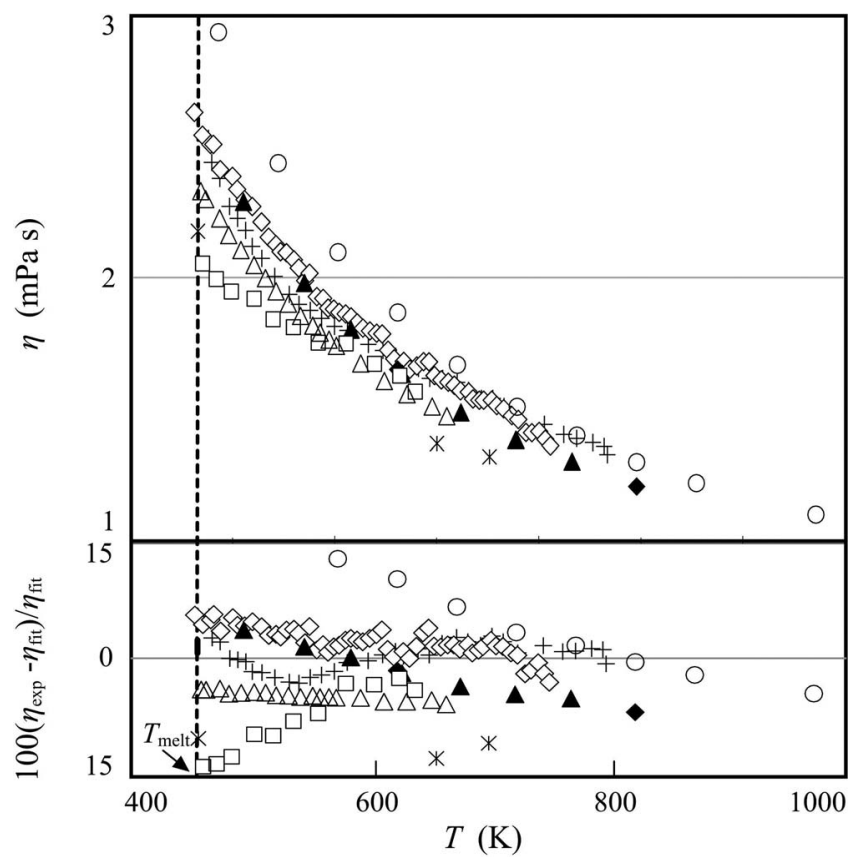

FIG. 6. Primary viscosity data and their percentage deviations from Eq. (2) for eutectic liquid alloy $\mathrm{Pb}+\mathrm{Sn}$ as a function of temperature. Slyarchuk et $a l^{34}{ }^{34}(+)$, Plevachuk et al. ${ }^{35}(\diamond)$, Thresh and Crawley ${ }^{19}(\diamond)$, Kanda and Colburn $^{36}(\boldsymbol{\Delta})$, Toye and Jones ${ }^{37}(*)$, Gebhardt and Kostlin ${ }^{20}(0)$, Jones and Davies $^{38}(\square)$, and Fisher and Phillips ${ }^{21}(\Delta)$.

\section{Conclusions}

The available experimental data for the density and viscosity of eutectic liquid alloys $\mathrm{Al}+\mathrm{Si}, \mathrm{Pb}+\mathrm{Bi}$, and $\mathrm{Pb}+\mathrm{Sn}$ have been critically examined with the intention of establishing a density and a viscosity standard. All experimental data have been categorized into primary and secondary data according to the quality of measurement, the technique employed, and the presentation of the data, as specified by a series of criteria. The proposed standard reference correlations for the density of eutectic liquid alloys $\mathrm{Al}+\mathrm{Si}, \mathrm{Pb}+\mathrm{Bi}$, and $\mathrm{Pb}+\mathrm{Sn}$ are characterized by deviations of $2.0 \%, 2.9 \%$, and $0.5 \%$ at the $95 \%$ confidence level. The standard reference correlations for the viscosity of liquid $\mathrm{Al}+\mathrm{Si}, \mathrm{Pb}+\mathrm{Bi}$, and $\mathrm{Pb}+\mathrm{Sn}$ are characterized by deviations of $7.7 \%, 14.2 \%$, and $12.4 \%$ at the $95 \%$ confidence level, respectively.

It is obvious that much more work, and certainly measurements with lower uncertainty, needs to be carried out in this area. The reference values proposed by this work represent the best that can be done with the present literature. Nevertheless, the deviations of the proposed equations are quite high and high enough, we judge, to be of concern in practical applications.

Finally, we note that the proposed correlations are for vaporliquid saturation conditions. Although in some applications, such as the flow in a tube or a nozzle, the pressure is higher than the saturation pressure, the pressure dependences of the density and the viscosity of liquid metal alloys are not sufficiently high that the variation exceeds the uncertainty in the correlations reported here. 


\section{Acknowledgments}

The authors would like to thank Ms. I. J. Armyra for her help in the early stages of this work. The work described in this paper was carried out under the auspices of the International Association for Transport Properties.

\section{References}

${ }^{1}$ M. J. Assael, K. Kakosimos, M. Bannish, J. Brillo, I. Egry, R. Brooks, P. N. Quested, K. C. Mills, A. Nagashima, Y. Sato, and W. A. Wakeham, J. Phys. Chem. Ref. Data 35, 285 (2006).

${ }^{2}$ M. J. Assael, A. E. Kalyva, K. E. Antoniadis, R. M. Banish, I. Egry, P. N. Quested, J. Wu, E. Kaschnitz, and W. A. Wakeham, J. Phys. Chem. Ref. Data 39, 033105 (2010).

${ }^{3}$ M. J. Assael, A. E. Kalyva, K. E. Antoniadis, R. M. Banish, I. Egry, J. Wu, E. Kaschnitz, and W. A. Wakeham, High Temp. - High Press. 41, 161 (2012).

${ }^{4}$ M. J. Assael, I. J. Armyra, J. Brillo, V. Stankus, J. Wu, and W. A. Wakeham, J. Phys. Chem. Ref. Data 41, 033101 (2012).

${ }^{5}$ M. J. Assael, M. L. V. Ramires, C. A. Nieto de Castro, and W. A. Wakeham, J. Phys. Chem. Ref. Data 19, 113 (1990).

${ }^{6}$ R. A. Khairulin and S. V. Stankus, J. Eng. Thermophys. 16, 188 (2007).

${ }^{7}$ T. Magnusson and L. Arnberg, Metall. Mater. Trans. A 32A, 2605 (2001).

${ }^{8}$ F. Siddiqui, T. Takahashi, M. Kudoh, and K. Ohsasa, Bull. Fac. Eng. Hokkaido Univ. Jpn. 136, 11 (1987)

${ }^{9}$ W. M. Wang, X. F. Bian, H. R. Wang, Z. Wang, L. Zhang, Z. G. Liu, and J.-M. Liu, J. Mater. Res. 16, 3592 (2001).

${ }^{10}$ J. Schmitz, B. Hallstedt, J. Brillo, I. Egry, and M. Schick, J. Mater. Sci. 47, 3706 (2012).

${ }^{11}$ P. S. Popel, E. L. Demina, E. L. Arkhangel'skii, and B. A. Baum, Teplofiz. Vys. Temp. 25, 487 (1987).

${ }^{12}$ L. Peijie, G. Jingjic, J. Jun, L. Qingchun, and R. Khosen, J. Rare Earths 14, 140 (1996).

${ }^{13}$ S. V. Stankus, R. A. Khairulin, A. G. Mozgovoi, V. V. Roshchupkin, and M. A. Pokrasin, High Temp. 44, 306 (2006).
${ }^{14}$ D. Yagodin, G. Sivkov, S. Volodin, and P. Popel, J. Mater. Sci. 40, 2259 (2005).

${ }^{15}$ B. B. Alchagirov, T. M. Shamparov, and A. G. Mozgovoi, High Temp. 41, 210 (2003).

${ }^{16}$ N. V. Kazakova, S. A. Lyamkin, and B. M. Lepinskikh, Zh. Fiz. Khim. 58, 1534 (1984).

${ }^{17}$ Y. Plevachuk, V. Sklyarchuk, G. Gerbeth, S. Eckert, and R. Novakovic, Surf. Sci. 605, 1034 (2011).

${ }^{18}$ L. Wang and A.-P. Xian, J. Electro. Mater. 34, 1414 (2005).

${ }^{19}$ H. R. Thresh and A. F. Crawley, Metall. Trans. 1, 1531 (1970).

${ }^{20}$ E. Gebhardt and K. Kostlin, Z. Metallkd. 48, 636 (1957).

${ }^{21}$ H. J. Fischer and A. Phillips, J. Met. 6, 1060 (1954).

${ }^{22}$ W. Gasior, Z. Moser, and J. Pstrus, J. Phase Equilib. 22, 20 (2001).

${ }^{23}$ P. S. Popel, E. L. Presnyakova, V. A. Pavlov, and E. L. Arkhangel'skii, Izv. Akad. Nauk SSSR, Met. (2), 53 (1985).

${ }^{24}$ V. Sobolev, J. Nucl. Mater. 362, 235 (2007).

${ }^{25}$ X. Song, X. Bian, J. Zhang, and J. Zhang, J. Alloys Compd. 479, 670 (2009).

${ }^{26}$ L. Moraru, Indian J. Pure Appl. Phys. 45, 733 (2007).

${ }^{27}$ H. R. Geng, R. Wang, Z. X. Yang, J. H. Chen, C. J. Sun, and Y. Wang, Acta Metall. Sin. (Engl. Lett.) 18, 159 (2005).

${ }^{28}$ M. A. Gusachev, N. Y. Kostantinova, P. S. Popel, and A. G. Mozgovoi, Thermophys. Aeromechanics 18, 469 (2011).

${ }^{29}$ Y. Plevachuk, V. Sklyarchuk, S. Eckert, and G. Gerbeth, J. Nucl. Mater. 373, 335 (2008).

${ }^{30}$ I. Kaban, W. Hoyer, Y. Plevachuk, and V. Sklyarchuk, J. Phys.: Condens. Matter 16, 6335 (2004).

${ }^{31}$ A. B. Kaplun, V. M. Shulaev, S. P. Linkov, and D. Y. Vartanov, The Thermophysical Properties of Substances and Materials (Kutateladze Institute of Thermophysics, USSR Academy of Sciences, Novosibirsk, 1979), p. 105.

${ }^{32}$ N. A. Nikol'skii, N. A. Kalakutskaya, I. M. Pchelkin, T. V. Klassen, and V. A. Vel'tishcheva, Teploenergetika (2), 92 (1959).

${ }^{33}$ Y. Wu, X. Bian, Q. Meng, Y. Zhao, T. Mao, and Y. Zhang, Mater. Lett. 61, 2434 (2007).

${ }^{34}$ V. Sklyarchuk, Y. Plevachuk, A. S. Yakimovich, L. I. Shtablavy, S. V. Stankus, and R. A. Khairulin, Thermophys. Aeromechanics 18, 123 (2011).

${ }^{35}$ Y. Plevachuk, V. Sklyarchuk, A. S. Yakimovich, B. Willers, and S. Eckert, J. Alloys Compd. 394, 63 (2005).

${ }^{36}$ F. A. Kanda and R. P. Colburn, Phys. Chem. Liq. 1, 159 (1968).

${ }^{37}$ T. C. Toye and E. R. Jones, Proc. Phys. Soc. 71, 88 (1958).

${ }^{38}$ W. R. D. Jones and J. B. Davies, J. Inst. Met. 86, 164 (1957).

${ }^{39}$ T. P. Yao and V. Kondic, J. Inst. Met. 81, 17 (1952). 